Table 3 Number (percentage) of patients whose blood pressure was out of control as judged by doctor

\begin{tabular}{lcc} 
Time (months) & 3 month group & $\mathbf{6}$ month group \\
\hline 12 & $63 / 302(21)$ & $52 / 300(17)$ \\
\hline 24 & $59 / 299(20)$ & $67 / 291(23)$ \\
\hline 36 & $50 / 275(18)$ & $41 / 260(16)$ \\
\hline
\end{tabular}

vided doctors with guidelines for levels of blood pressure that should be considered out of control, we asked them to use their own judgment.

\section{Satisfaction with medical care}

All of the factors measured for patient satisfaction were equivalent in the two groups, as was patients' satisfaction with the care of their blood pressure by their doctor (see bmj.com). More patients in the six month group thought that the doctor did not take their blood pressure problem seriously enough towards the end of the study.

\section{Adherence to treatment}

Adherence to treatment was equivalent between groups. However, we found that pill counts in this pragmatic trial were unreliable.

\section{Discussion}

The findings of this study suggest that six monthly follow up is sufficient for patients with controlled hypertension. In three years of follow up of patients with hypertension, we found that blood pressure control, patient satisfaction, and adherence to treatment were equivalent in patients assigned to follow up at three month and six month intervals.

Patients in both groups visited their doctor more frequently than their assigned follow up times, but the six month group had fewer visits to the doctor overall. Patients in this group had more visits unrelated to hypertension, which suggests that patients given longer intervals between regular appointments see their doctor between these appointments for other reasons. We do not know if these other issues would have been dealt with at the regular hypertension visit if shorter intervals had been used.

As the study included patients from 50 family doctors in Canada who practise in a variety of rural and

\section{What is already known about this topic}

Recommendations of current hypertension guidelines from Canada, Britain, and the United States for the follow up of patients with stable hypertension are based on expert opinion or usual practice

The decision about the frequency of follow up of a chronic disease such as hypertension has important implications for hypertension control by family doctors and the cost of care

\section{What this study adds}

Follow up of patients with treated hypertension every six months is equivalent to every three months for mean blood pressure, blood pressure control, patient satisfaction, and adherence to hypertensive drugs

Blood pressure of $20 \%$ of patients was out of control when assessed at yearly intervals over three years in both groups urban settings, its findings can be generalised to most family practice settings in North America and Britain.

We found a high rate of inadequately controlled blood pressure in patients in both groups. The higher mean blood pressure at entry and the level of control may result from the higher acceptable targets for blood pressure in older recommendations for control of blood pressure, which were used initially. It may also explain why blood pressure in both groups fell during the 36 months of follow up. Determining the reasons for this fall was not part of this study, but the results suggest that frequency of follow up is not as important in blood pressure control as has been thought. The quality of the doctor-patient encounter, the doctor's awareness of guidelines, clinical inertia," and the view of "treating the patient rather than treating the number" may all contribute to the large numbers of known hypertensive patients whose blood pressure is out of control.

The following family practitioners participated in the study: M Bala, W Beck, P Bell, S Blanchard and E Nancekievill, D Briggs, H Bright, M Browne, N Burget, G Burke, B. Campbell-Unger, T Clarke, I Crawford, L Dempsey, P Farmer, M K Gazendam, J Griffiths, B Hart, J Henstock, S Hinton, N Hobbs, P Johannsson, B Kain, P Kenny, D Koval, C Lawlor, R Lees, S M Lim, K Lockington, D MacLean, D Marcassa, M McCall, V Mohr, J Molson, A Newman, C Newton, P O’Donnell, B Parker, G Patey, C Pettis, D Pinkerton, J Raleigh, C Rice, T Richards, S Sangster-Gibson, K Schultz, J Sloan, L Stewart, T Touzel, S Verma, R Wilson, and D Wyatt.

Contributors: See bmj.com

Funding: Canadian Institute for Health Research; McKnight Fund of Queen's University.

Competing interests: None declared.

Ethical approval: Queen's University Research Ethics Board.

1 Joint National Committee on Prevention, Detection, Evaluation, and Treatment of High Blood Pressure. Sixth report. Bethesda: National Institutes of Health, 1997. (NIH publication No 98-4080.)

2 Joffres MR, Hamet P, MacLean DR, Litalien GL, Fodor G. Distribution of blood pressure and hypertension in Canada and the United States. AJH 2001:14:1099-105.

3 Burt VL, Cutler JA, Higgins M, Horan MJ, Labarthe D, Whelton P, et al. Trends in the prevalence, awareness, treatment, and control of hypertension in the adult US population. Data from the health examination surveys, 1960 to 1991. Hypertension 1995;26:60-9.

4 Chobanian AV, Bakris GL, Black HR, Cushman WC, Green LE, Izzo JL, et al. The seventh report of the Joint National Committee on Prevention, Detection, Evaluation, and Treatment of High Blood Pressure. JAMA 2003;289:2560-72.

5 Ramsay LE, Williams B, Johnston GD, MacGregor GA, Poston L, Potter $\mathrm{JF}$, et al for the British Hypertension Society. Guidelines for management of hypertension: report of the third working party of the British Hypertension Society. J Hum Hypertensn 1999;13:569-92.

6 Canadian Hypertension Recommendations Working Group. The 2001 Canadian Hypertension Recommendations Working Group. The 2001 Canadian hypertension recommendations. What is
but still important. Can J Cardiol 2002;18:591-603.

7 Baker R. Development of a questionnaire to assess patients' satisfaction with consultations in general practice. BrJ Gen Pract 1990;40:487-90.

8 Baker R. Dialogue 3rd edition, a method for surveying patient satisfaction Leicester: Clinical Governance Research and Development Unit, Department of General Practice and Primary Health Care, University of Leicester, 2001.

9 Phillips LS, Branch WT, Cook CB, Doyle JP, El-Kebbi IM, Gallina DL, et al. Clinical inertia. Ann Intern Med 2001:135:825-34.

(Accepted 26 November 2003)

doi 10.1136/bmj.37967.374063.EE

\section{Endpiece}

\section{Life according to Wilde}

The old believe everything; the middle aged suspect everything; the young know everything. Oscar Wilde (1854-1900)

Fred Charatan, retired geriatric physician, Florida 